\title{
A Spatiotemporal Analysis and Dispersal Patterns of the Potato Cyst Nematode Globodera pallida in Idaho
}

\author{
J. B. Contina, ${ }^{1}$ L. M. Dandurand, ${ }^{1, \dagger}$ and G. R. Knudsen ${ }^{2}$ \\ ${ }^{1}$ Department of Entomology, Plant Pathology and Nematology, University of Idaho, Moscow, ID 83844-2329 \\ 2 Department of Soil and Water Systems, University of Idaho, Moscow, ID 83844-2340 (deceased) \\ Accepted for publication 30 September 2019.
}

\begin{abstract}
The potato cyst nematode Globodera pallida is a globally regulated potato pest. It was detected for the first time in the United States in the state of Idaho in 2006, and as of February 2019, the infestation is limited to 1,326 hectares. G. pallida is a specialized obligate sedentary endoparasite that can survive in the soil for up to 30 years in the absence of its potato host. In highly infested fields, the nematode can reduce tuber yields up to $80 \%$ and is spread mainly through the movement of soil, tubers, or farm equipment. The objectives of this study were to describe the spatiotemporal pattern of G. pallida in infested fields and model its dispersal patterns in southeastern Idaho. We used geostatistical tools and simulation models for precise mapping and to describe the relationships between $G$. pallida incidence and the spatial configurations. We found that the nematode is spatially clustered and prevalent around edges of fields, and its dispersal pattern followed the direction of cultivation. We found that the absence of potato in an infested field significantly reduced the number of cysts sampled each year subsequent to the initial delimitation
\end{abstract}

ABSTRACT

sampling in 2007. Phytosanitary measures prohibiting the growth of potato contributed to stopping nematode reproduction, and the use of chemical fumigants and biofumigant cover crops contributed to a significant reduction in egg viability. We observed a process of a nonlinear decline in the prevalence of cysts as the distance separation from the primary infestation focus increased. A power law model was used to fit G. pallida dispersal capabilities. This study contributed to describing G. pallida infestation for Idaho. The goal of this study is to provide information on the spatial pattern and landscape ecology of G. pallida in Idaho for policy makers, industry, and researchers as well as facilitate common understandings on the challenges and opportunities for controlling this pest in Idaho.

Keywords: Akima, ecology and epidemiology, Globodera pallida, invasive species distribution modeling, kriging, nematology, potato cyst nematodes, power law model, quarantine pest, spatial analysis, spatial autocorrelation
Phytopathogenic nematodes represent a considerable threat to food security worldwide. Around 4,100 species of plant-parasitic nematodes have been identified, and they cause between $\$ 80$ and $\$ 118$ billion per year in crop losses (Koenning et al. 1999; Sasser and Freckman 1987). The potato cyst nematode Globodera pallida, also known as the pale cyst nematode (Behrens 1975; Stone 1972), is a globally regulated potato pest. G. pallida and the golden nematode Globodera rostochiensis (Skarbilovich 1959; Wollenweber 1923), both potato cyst nematodes, coevolved with potato and other native Solanum species in the Andean region of South America (Picard et al. 2004). A recent survey revealed that G. rostochiensis is present in 68 countries and that G. pallida is present in 48 countries (CABI 2018). G. pallida is a specialized obligate sedentary endoparasite that can survive in the soil for up to 30 years in the absence of its potato host (Turner 1996). In highly infested fields, G. pallida can reduce tuber yields up to $80 \%$ and is spread mainly through the movement of soil, tubers, or farm equipment (Contina et al. 2019; Talavera et al. 1998; Vasyutin and Yakovleva 1998).

G. pallida was found in southeastern Idaho in 2006 in two potato fields in Bingham County (Hafez et al. 2007; USDA-APHIS 2019). The U.S. Department of Agriculture (USDA)-Animal and Plant

†Corresponding author: L. M. Dandurand; 1md@uidaho.edu

Funding: Funding for this research was provided by the U.S. Department of Agriculture National Institute of Food and Agriculture grant 2015-69004-23634.

*The $\boldsymbol{e}$-Xtra logo stands for "electronic extra" and indicates that five supplementary figures are published online.

The author(s) declare no conflict of interest.

(C) 2020 The American Phytopathological Society
Health Inspection Service (APHIS) and the Idaho State Department of Agriculture (ISDA) have listed G. pallida as a quarantine pest under Title 7 Code of Federal Regulations 301.86 and IDAPA (Idaho Administrative Procedure Act) 02.06.10, respectively. The current regulated area includes portions of northern Bingham and southern Bonneville counties, and it is, as of February 2019, limited to 3,057 ha, of which 1,326 ha are fields infested with G. pallida (USDA-APHIS 2019). G. pallida spread followed a contagion effect scenario, where infested fields contributed to the infestation of nearby fields, probably through the movement of soilcontaminated agricultural equipment (Contina et al. 2018). The detection of G. pallida in Idaho is potentially associated with one introduction, and the nematode population growth in the area was maintained through local reproduction rather than multiple new introductions (Blok and Phillips 2012; Contina et al. 2018).

The USDA-APHIS and the ISDA have implemented a containment and eradication program to prevent G. pallida spread to other potato fields. In infested fields, the program outlines (i) restrictions on the movement of soil and plant materials, (ii) prohibition of planting potato and other solanaceous crops, and (iii) sanitation requirement for farm equipment. Soil fumigation with the nematicide Telone II (1,3-dichloropropene; Dow AgroSciences) is being conducted in infested fields as part of the G. pallida eradication program, and Solanum sisymbriifolium 'litchi tomato' is under field-scale trials in infested fields (USDAAPHIS 2019). S. sisymbriifolium is recognized as a trap crop for both G. pallida and G. rostochiensis (Dias et al. 2012; Timmermans et al. 2006), and a 2016 study showed that the $G$. pallida reproduction rate was significantly reduced by $99 \%$ in potato following $S$. sisymbriifolium compared with both the potato-followingfallow and the potato-following-potato treatments (Dandurand and Knudsen 2016). The USDA-APHIS has issued a list of regulated articles: (i) G. pallida; (ii) G. pallida host crops (eggplant 
[Solanum melongena], pepper [Capsicum spp.], potato [Solanum tuberosum], tomatillo [Physalis philadelphica], and tomato [Solanum esculentum]); (iii) root crops; (iv) garden and dry beans (Phaseolus spp.) and peas (Pisum spp.); (v) all nursery stock; (vi) soil, compost, humus, muck, peat, and manure; (vii) hay, straw, and fodder; and (viii) any equipment or conveyance used in an infested or associated field that can carry soil if moved out of the field. The USDA-APHIS provides steps for deregulating G. pallida-infested fields: (i) no viable eggs detected (collected eggs are tested for viability), (ii) three rounds of greenhouse bioassay of field cysts to confirm absence of reproduction, and (iii) in-field bioassay, where fields can be released from quarantine status after negative viability surveys after harvests of three susceptible crops. As of 2019, 22 fields (969 ha) have passed step i (no viable eggs found), and 18 fields (720 ha) have passed step ii (no reproduction) (USDA-APHIS 2019).

International trade represents an important invasion pathway for nonnative plant pests. Pest invasion consists of several phases (Ferris et al. 2003): (i) entry of the organism, (ii) establishment through local reproduction, (iii) integration into the local environment, and (iv) spread. Because of these risks, international trade agreements and phytosanitary regulations were established and reinforced to minimize risks of accidental introduction of plant pests to nonnative areas. The International Plant Protection Convention defines "quarantine pest" as "a pest of potential economic importance to the area endangered thereby and not yet present there, or present but not widely distributed and being officially controlled" (FAO-IPPC 2017). To avoid severe economic losses owing to the entry of nonnative plant diseases, a comprehensive understanding of the spatiotemporal and dispersal patterns of the pathogens is warranted to better manage and control disease epidemics that could potentially devastate our food provision and energy resources.

Spatial statistics are based on the assumption that sample units may be associated with each other. Whereas traditional statistical theory is based on assumed independent observations, spatial analyses assume nonindependence of observations and allow for measurement of the degree of association between observations as a function of distance and a description of statistically significant nonindependence. Georeferenced data denote the locations and time periods when events are recorded from a continuous surface occupying a fixed subset, $D$, of two-dimensional space $\left(R^{2}\right)$ and where the attribute value $\left(Z\left[s_{i}\right]\right)$ is a random vector at location $s_{i}$ in $D$ (Cressie 1993). Spatial data comprised all surfaces that share a common border or have a direct transport connection with neighbors, which could capture interaction flows between areas (Haining 2003). Space-time events possess an intrinsic continuity or structure that enables the formulations of predictive models, and the concept of spatial continuity is often referred to as "Tobler's First Law of Geography," where "[e]verything is related to everything else, but near things are more related than distant things" (Tobler 1970). The concept of spatial continuity is translated in the spatial context as follows (Haining 2003). (i) If the attribute values of one point location are similar to those of another location (spatial dependence), this process is known as a positive spatial autocorrelation. (ii) As the distance separation between observations increases, such autocorrelation will tend to weaken, and the attribute values will appear to be spatially independent; this process is known as a negative spatial autocorrelation.

Exploratory spatial analysis provides a collection of visual and essential mapping tools to detect and assess spatial patterns and formulate hypotheses. The Akima interpolation method is a mathematical model based on a piecewise function composed of a set of polynomials each of degree 3 , and it is a continuously differentiable subspline interpolation (Akima 1970, 1991). Data from next neighbor are used to determine the coefficients of the interpolation polynomial. Ordinary kriging is used as a probabilistic interpolator to estimate the value of a random variable, $z$, at one or more unsampled points. The kriging estimate of variable $z$ at point $x_{0}, \hat{z}\left(x_{0}\right)$, is a linear weighted sum of $n$ observations surrounding the estimate and provides minimum mean-squared error values at unsampled locations (Cressie 1993; Haining 2003). Experimental variograms represent a description of the spatial continuity of the data and are calculated using a measure of variability between pairs of points at various distances (Matheron 1963).

The spread of plant diseases across a landscape creates a definite and measurable trend known as the disease dispersal gradient (Gregory 1968; Mundt et al. 2009; Severns et al. 2019). The disease dispersal gradient implies that the intensity of disease varies systematically with distance from the original source of disease inoculum (Gregory 1968). There are two basic types of biological dispersal: (i) density-independent or passive dispersal that depends on humans, animal, and environmental factors for dispersal, such as in the case of plant-parasitic nematodes (Nathan 2001); and (ii) density-dependent or active dispersal that depends on factors like local population size, resource competition, and environmental conditions, such as in the case of some plantparasitic fungi (Bowler and Benton 2005). Discontinuous dispersal in infested fields may result in the establishment of isolated pest foci from the main infestation focus using a shortdistance dispersal (SDD) mechanism facilitated by passive transportation (human activities). The combination of longdistance dispersals (LDDs) and SDDs is considered to be stratified and consists of (i) the establishment of new foci far from the moving population front, (ii) the growth and development of individual foci, and (iii) the fusion of foci that contributes to the advance of the population front (Hengeveld 1989). Choi et al. (2017) reported that the pine wood nematode, Bursaphelenchus xylophilus, invasion consisted of a jumping type of dispersal and the formation of new patches that later expanded and merged, supporting the existence of a stratified dispersal pattern for B. xylophilus. Madden et al. (2007) categorized the disease dispersal gradient as (i) primary gradient, where all infestations are originating at the initial inoculum source or focus (primary spread of the disease), which occurs for monocyclic diseases; and (ii) secondary gradient, where infections are owing to inoculum produced beyond the initial inoculum source (secondary spread of the disease), which occurs for polycyclic diseases.

Nonlinear models of disease dispersal have been developed to capture the determinants of disease spread. The negative exponential and power law are the most widely used contact distribution models in plant disease epidemiology (Madden et al. 2007; Mundt 1989). Both models explain a process of a nonlinear decline in inoculum prevalence as the distance increases; however, for the power law model, the gradient is steeper near the source and shallower far from the source compared with the exponential model (Madden et al. 2007). Power law models were used in plant nematology for estimating sampling surveys in infested fields (Duncan et al. 1989; McSorley et al. 1985), determining the aggregation of several nematode species in soil (Boag and Topham 1984), and classifying soil nematode communities in urban landscapes (Park et al. 2013). Dispersal models convey important information on (i) the spatial behavior of nonnative pests, (ii) the identification of vulnerable areas, and (iii) the provision of a framework for predicting and controlling pest invasions.

The objectives of this study were to describe the spatiotemporal distribution of G. pallida in infested fields and model its dispersal patterns in southeastern Idaho. We proceeded in characterizing the distribution of G. pallida in infested fields during the first year of detection and after application of fumigants and planting of nonhost crops in subsequent years. Because the distribution and abundance of invasive nematode species are often correlated with human activities and land use practices, we simulated the spatial 
spread of G. pallida in a potato field using the invasive species distribution modeling (ISDM) (Hattab et al. 2017; Meentemeyer et al. 2008). We calculated the distance separation between the main G. pallida inoculum source focus from the rest of the foci in fields and between fields, and we fit a power law model to the distribution of foci in to estimate SDD and LDD parameters for G. pallida. Finally, we concluded our study by discussing the implications of understanding the spatiotemporal and dispersal patterns of G. pallida as well as comparing and exploring the strength and limitations of our models. The main goal of this study is to provide information on spatial patterns of G. pallida and enable a provisional framework for population prediction and control.

\section{MATERIALS AND METHODS}

Data collection. Data point locations of fields infested with G. pallida in southeastern Idaho with the associated number of cysts and the values of egg viability were collected by the USDAAPHIS from 2006 to 2014 (Fig. 1 and Table 1). The sampling system used by the USDA-APHIS began by dividing infested fields into $20 \times 20$-m grids. For each grid, $2.27 \mathrm{~kg}$ of soil $(5$ pounds) was collected in a full-field sampling scheme during the first year of detection to determine the location of the infestation foci and $9.07 \mathrm{~kg}$ of soil (20 pounds) was collected in infested grids after each application of fumigants and planting of nonhost crops in subsequent years to evaluate and monitor the eradication progress (Supplementary Fig. S1) (USDA-APHIS 2009, 2017a, b, 2018). Methyl bromide (Bromomethane), currently not in use, and Telone II (1,3-dichloropropene) were used as fumigants. Raphanus spp. (radish), Trifolium spp. (clover), and Eruca spp. (arugula) were used as biofumigant cover crops. The soil taxonomy associated with the infested fields is mostly inside the Bannock series and consists of deep, well-drained soils formed in medium-textured alluvium over gravel and sand (NCSS 2002). The taxonomic class is coarse loamy over sandy or sandy skeletal, mixed, superactive, frigid Aridic Calcixerolls (NCSS 2002).

The identity of G. pallida was confirmed by morphological and molecular methods (Skantar et al. 2007). G. pallida cysts were extracted from soil samples using the USDA cyst extraction method (USDA-APHIS 2009). Egg viability was assessed using Meldola Blue as the staining agent (Ogiga and Estey 1974). The values of cysts were $\log _{10}$ transformed (cysts per $1 \mathrm{~kg}$ of soil +1 ) to standardize the variance, and the values of eggs viability were expressed in percentage. The data collected are represented as a set of marked points illustrated in algebraic terms as

$$
y=\left\{\left(x_{1}, m_{1}\right), \ldots,\left(x_{n}, m_{n}\right)\right\}
$$

where $x_{i}$ are the point centroid of each grid represented as easting and northing and expressed in meters and $m_{i}$ are the number of cysts collected or the values of egg viability.

Deterministic spatial modeling. The Akima interpolation model was used to build a raster-based map of G. pallida distribution in infested fields. The Akima method is a mathematical model based on a continuously differentiable subspline interpolation function composed of a set of cubic polynomials (Akima 1970, 1991). Data from next neighbor are used to determine the coefficients of the interpolation polynomial. The model is defined as follows.

For a set of data points,

$$
s_{i}=s\left(x_{i}\right), \quad 1 \leq i \leq k
$$

The interpolation function is defined as

$$
s(x)=a_{0}+a_{1}\left(x-x_{i}\right)+a_{2}\left(x-x_{i}\right)^{2}+a_{3}\left(x-x_{i}\right)^{3}, \quad x_{i} \leq x \leq x_{i}+1
$$

where $a_{0}, a_{1}, a_{2}$, and $a_{3}$ are the coefficients of the interpolation polynomial for each interval $\left[x_{i}, x_{i+1}\right]$. The Akima spline interpolation is characterized by its nonlinearity, and it is less affected by outliers.

Stochastic spatial modeling. The ordinary kriging was used as a probabilistic interpolator to estimate the value of a random variable, $z$, at one or more unsampled points. The kriging estimate of variable $z$ at point $x_{0}, \hat{z}\left(x_{0}\right)$, is a linear weighted sum of $n$ observations surrounding the estimate (Stein 1999):

$$
\hat{z}\left(x_{0}\right)=\sum_{i=1}^{n} \lambda_{i} z\left(x_{i}\right)
$$

where $\lambda_{i}$ are the weights and $z\left(x_{i}\right)$ is the known value of variable $z$ at sampling site $x_{i}$.

We estimated the index of dispersion $(D)$ by calculating the average variance-to-mean ratio as defined by

$$
D=\frac{\sigma^{2}}{\mu}
$$

where $\sigma^{2}$ is the estimated variance and $\mu$ is the estimated mean of cysts from the kriging interpolation output. The index of dispersion was used to determine whether the distributions of cysts in the fields were clustered or dispersed compared with the randomness associated with a Poisson process. The index of dispersion ranges from 0 to 1 , where (i) $(D=0)$ represents a constant distribution (not dispersed), (ii) $0<D<1$ represents a binomial distribution (underdispersed or clustered), (iii) $D=1$ represents a Poisson distribution (uniformly dispersed), and (iv) $D>1$ represents a negative binomial distribution (overdispersed).

Kriging, as a probabilistic interpolator, relies on an experimental variogram to measure the spatial correlation of the random function

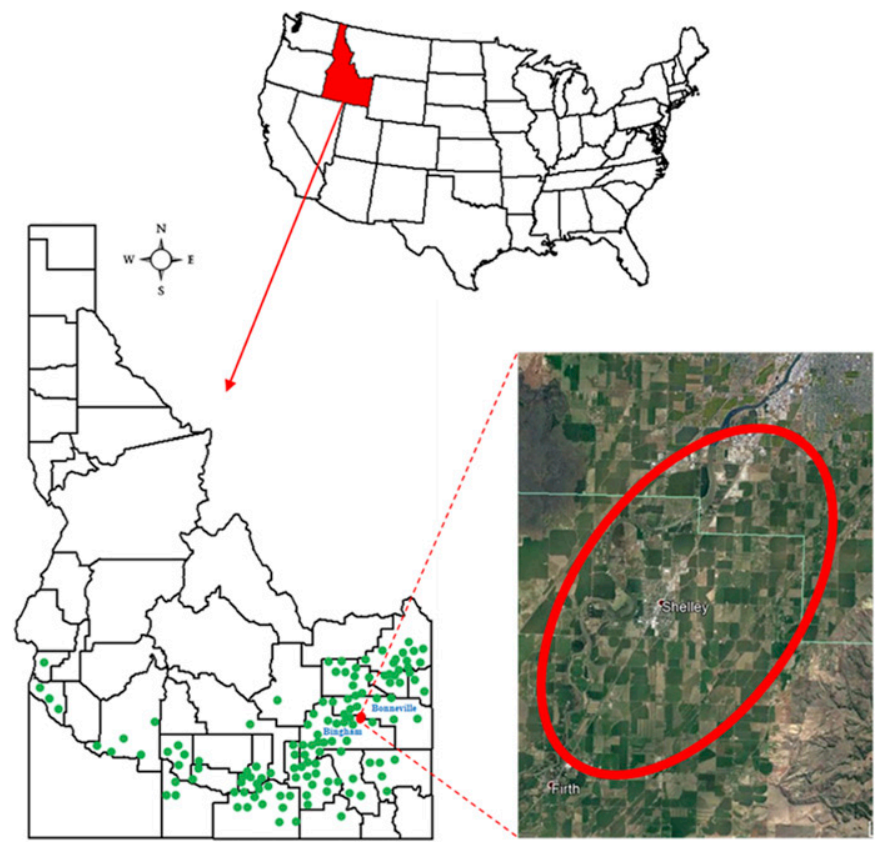

Fig. 1. Map of the state of Idaho (left) and location of the potato fields infested with Globodera pallida in southeastern Idaho (right). The distribution of potato fields along the Snake River (USDA-NASS 2012) are represented by gray/ green dots, and the fields infested with G. pallida are inside the ellipse. The infestation area spans over a diameter of $25 \mathrm{~km}$ and encompasses the counties of Bonneville and Bingham. 
$\hat{z}\left(x_{0}\right)$ (Stein 1999). The variogram is defined by calculating the semivariance as a function of distance:

$$
\gamma(d)=\frac{1}{2} \sum\left\{\left[\hat{z}\left(x_{1}\right)-\hat{z}\left(x_{2}\right)\right]^{2}\right\}
$$

The semivariance increases with increasing lag distance (monotonic increasing), which indicates the presence of spatial autocorrelation and that, within a certain distance, the values of $\hat{z}(x)$ correlate with space (spatial dependence); however, as the lag distance increases, values become increasingly independent of each other (spatial independence) to reflect the absence of spatial autocorrelation. If the spatial dependence varies along with spatial directions (anisotropy), the process is modeled using directional variograms as defined by

$$
\gamma(d, \theta)=\left(\frac{1}{2} N(d, \theta)\right) \sum_{i=1}^{N(d, \theta)}\left[\hat{z}\left(x_{1}\right)-\hat{z}\left(x_{2}+h, \theta\right)\right]^{2}
$$

where $\theta$ represents the directional angles along the point locations.

ISDM. Invasive species modeling was used as a spatial simulation to characterize the spread of G. pallida in a potato field and produce risk maps of occurrence likelihood in the absence of control measures. The force of invasion $\left(F_{i}\right)$ was calculated as a negative exponential dispersal kernel using the formula (Meentemeyer et al. 2008)

$$
F_{i}=\Sigma_{k=1}^{N} \exp \left(\frac{-d_{i k}}{a}\right)
$$

where $d_{i k}$ is the Euclidean distance between each initial nematode focus of invasion $k$ in a target area $i$. The parameter $a$ represents the form of the dispersal kernel, where low values of $a$ indicate high dispersal limitation and high values indicate low dispersal limitation.
In this study, we established that G. pallida dispersal capabilities and limitations are closely related to the level of human activities in the fields and represent the form of the dispersal kernel. We defined human activities as the work required for field tillage, planting, harvesting and maintenance, and transit of agricultural tools and machinery. G. pallida dispersal is characterized as densityindependent or passive transmission that requires human activity for movement of cyst-infested material from contaminated to noncontaminated areas.

G. pallida dispersal and inoculum gradients. The distance separation between the primary inoculum focus and secondary foci of $G$. pallida in fields (SDD) was calculated using a distance-based matrix. The same method was used to estimate distance separation between the most infested field and the less infested fields (LDD) as illustrated in algebraic terms:

$$
d_{i j}=d\left(\left\{X_{i}\right\},\left\{X_{j}\right\}\right)=X_{i}-X_{j} 2
$$

where $d_{i j}$ is the pairwise distance between major inoculum focus $X_{i}$ and minor foci $X_{j}$, and they are arranged in a matrix. A power law model was used to fit the distribution prevalence of G. pallida cysts over increasing distances (Gregory 1968; Madden et al. 2007):

$$
Y=a_{P} s^{-b_{p}}
$$

where $a_{P}$ and $b_{p}$ are parameters and $s$ is the distance separation from the inoculum source. The model describes a nonlinear decline in inoculum prevalence as distance increases, with a steeper gradient near the inoculum source and a shallower gradient far from the source, while illustrating a fat-tail distribution.

Data analysis and modeling. The software $\mathrm{R}$ version 3.5.2 was used as a modeling language environment for data exploration

\begin{tabular}{|c|c|c|c|c|c|c|c|c|c|c|}
\hline Field $^{a}$ & Area, ha & $\begin{array}{l}\text { Sampling } \\
\text { coverage }\end{array}$ & $\begin{array}{l}\text { Number of } \\
\text { grids }\end{array}$ & $\begin{array}{l}\text { Sampling size, } \\
\mathrm{kg} \text { of soil/grid }\end{array}$ & Year & $\begin{array}{c}\text { Total sampled } \\
\text { soil, kg }\end{array}$ & $\begin{array}{c}\text { Total cysts } \\
\text { collected }\end{array}$ & $\begin{array}{c}\text { Cysts/kg of } \\
\text { soil }\end{array}$ & $\begin{array}{l}\text { Eggs/g } \\
\text { of soil }\end{array}$ & $\begin{array}{c}\text { Average eggs } \\
\text { viability, \% }\end{array}$ \\
\hline \multirow[t]{6}{*}{ Bin001 } & 18.29 & Full field & 469 & 2.27 & 2007 & 1,065 & 6,410 & 6.02 & 0.60 & 12.46 \\
\hline & & Monitoring grids & 76 & 9.07 & 2009 & 2,068 & 67,116 & 32.46 & 3.25 & 1.02 \\
\hline & & & & & 2010 & 1,379 & 54,538 & 39.55 & 3.96 & 0.28 \\
\hline & & & & & 2011 & 1,379 & 54,054 & 39.20 & 3.92 & 0.13 \\
\hline & & & & & 2012 & 689 & 13,155 & 19.09 & 1.91 & 0.00 \\
\hline & & & & & 2014 & 689 & 14,093 & 20.45 & 2.04 & 0.00 \\
\hline \multirow[t]{4}{*}{ Bin025 } & 89.52 & Full field & 2,374 & 2.27 & 2007 & 5,389 & 277,496 & 51.49 & 5.15 & 20.03 \\
\hline & & Monitoring grids & 59 & 9.07 & 2009 & 1,605 & 471,074 & 293.50 & 29.35 & 0.36 \\
\hline & & & & & 2010 & 1,070 & 381,545 & 356.58 & 35.66 & 0.21 \\
\hline & & & & & 2011 & 535 & 121,494 & 227.04 & 22.70 & 0.00 \\
\hline \multirow[t]{5}{*}{ Bin026 } & 55.08 & Full field & 1,415 & 2.27 & 2007 & 3,212 & 8,347 & 2.60 & 0.26 & 17.69 \\
\hline & & Monitoring grids & 97 & 9.07 & 2009 & 2,639 & 54,881 & 20.80 & 2.08 & 0.22 \\
\hline & & & & & 2010 & 1,760 & 44,864 & 25.49 & 2.55 & 0.18 \\
\hline & & & & & 2011 & 1,760 & 37,277 & 21.18 & 2.12 & 0.02 \\
\hline & & & & & 2012 & 880 & 16,211 & 18.43 & 1.84 & 0.00 \\
\hline \multirow[t]{4}{*}{ Bin054 } & 57.91 & Full field & 1,468 & 2.27 & 2007 & 3,332 & 3,861 & 1.16 & 0.12 & 33.31 \\
\hline & & Monitoring grids & 62 & 9.07 & 2009 & 1,687 & 32,180 & 19.08 & 1.91 & 0.58 \\
\hline & & & 60 & & 2010 & 1,088 & 23,227 & 21.35 & 2.13 & 0.16 \\
\hline & & & 60 & & 2011 & 1,088 & 18,595 & 17.09 & 1.71 & 0.14 \\
\hline \multirow[t]{4}{*}{ Bin068 } & 57.87 & Full field & 1,485 & 2.27 & 2008 & 3,371 & 295 & 0.09 & 0.009 & 9.32 \\
\hline & & Monitoring grids & 22 & 9.07 & 2009 & 599 & 1,671 & 2.79 & 0.28 & 3.17 \\
\hline & & & & & 2010 & 399 & 853 & 2.14 & 0.21 & 0.74 \\
\hline & & & & & 2011 & 200 & 216 & 1.08 & 0.11 & 0.00 \\
\hline \multirow[t]{4}{*}{ Bon064 } & 60.91 & Full field & 1,515 & 2.27 & 2007 & 3,439 & 1,964 & 0.57 & 0.06 & 36.08 \\
\hline & & Monitoring grids & 74 & 9.07 & 2009 & 2,014 & 10,913 & 5.42 & 0.54 & 0.68 \\
\hline & & & & & 2010 & 1,342 & 9,318 & 6.94 & 0.69 & 0.48 \\
\hline & & & & & 2011 & 1,342 & 6,310 & 4.70 & 0.47 & 0.30 \\
\hline
\end{tabular}
and spatial analysis in this study (R Core Team 2018). Analysis of variance was performed to analyze G. pallida prevalence in infested fields. Tukey's honest significant difference (HSD) test was performed

TABLE 1. Sampling of fields infested with Globodera pallida and the impact of eradication measures on eggs viability

a Direction of cultivation was north/south for all fields except Bon064, which was east/west. 
to compare the temporal mean differences with significant differences occurring at level $P \leq 0.05$. Centroid coordinates of the field grids were projected into easting and northing coordinate system using the spatial reference EPSG:3524 NAD83 in the package "sp." Akima interpolation was performed using the packages "akima" and "fields" (Akima 1970, 1991). Ordinary kriging and the variogram modeling were performed using the packages "gstat" and "automap." The "automap" package automatically fits a variogram to the data and provides initial estimates for the sill (variance), range (distance at which the variogram reaches the sill), nugget (error measurement), and $\kappa$ (a smoothing parameter). A kriging prediction and standard error maps were also generated in this procedure. ISDM was computed using the packages "iSDM" and "raster" (Hattab et al. 2017). Short-distance distribution and long-distance distributions were plotted and model fit using the packages "ggplot2," "MASS," "plyr," and "nls2."
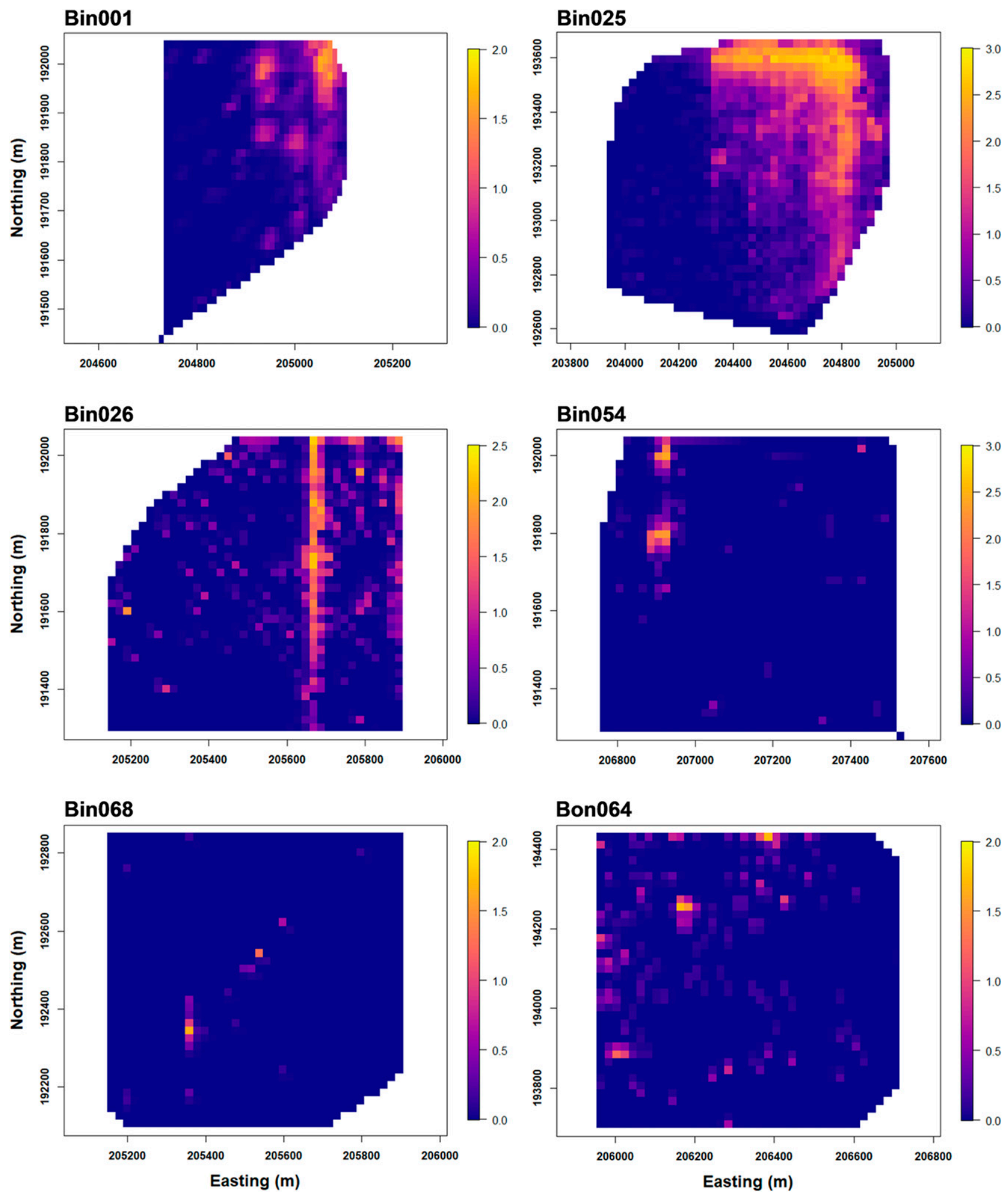

Fig. 2. Distribution of Globodera pallida cysts in infested fields using the Akima spatial interpolation method. The number of cysts is $\log _{10}$ transformed per kilogram of soil. 


\section{RESULTS}

The Akima interpolation method showed that G. pallida cysts are spatially clustered, with the greatest prevalence at the edge and entrance of each field. For the first year of G. pallida detection in Idaho, we analyzed the nematode distribution in six fields (Bin001, Bin025, Bin026, Bin054, Bin068, and Bon064), and we found the presence of multiple infestation foci with high cyst densities (Fig. 2). The number of infestation foci per field was

\section{Bin001}

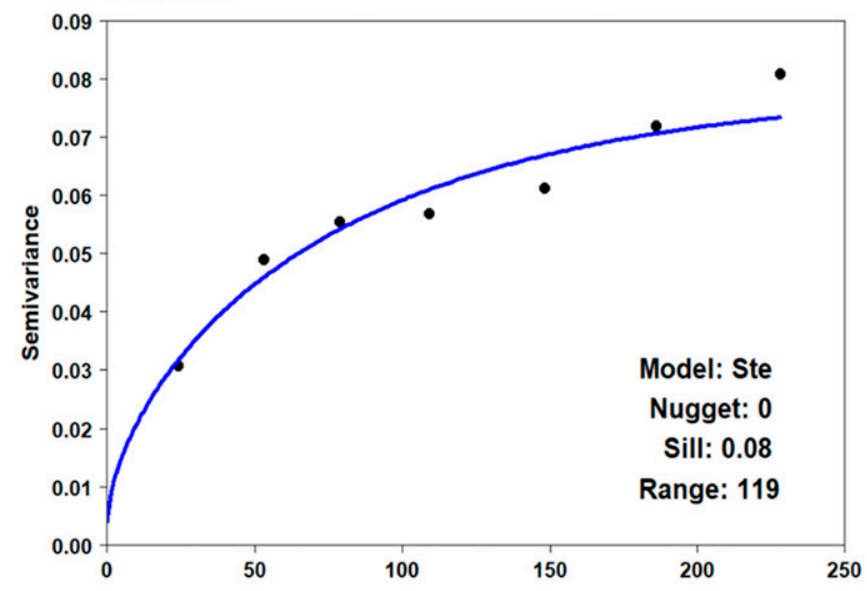

\section{Bin026}

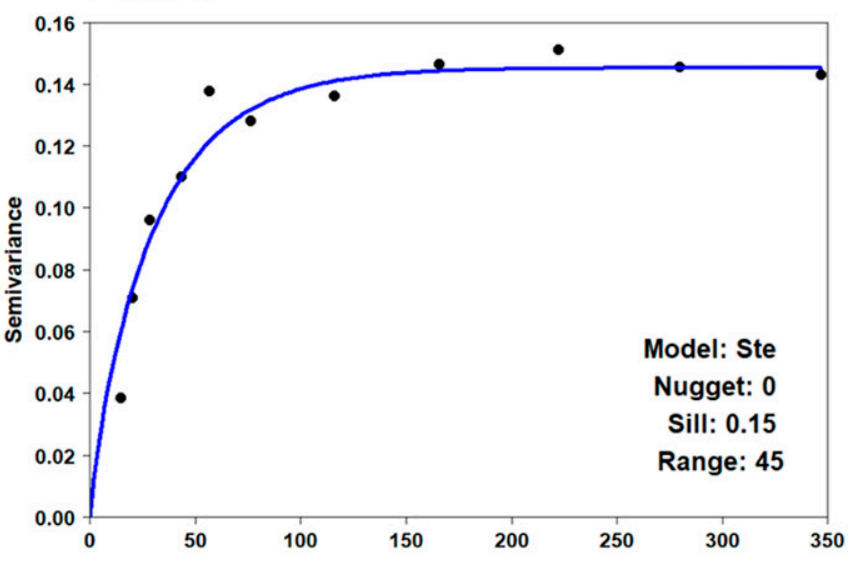

\section{Bin068}

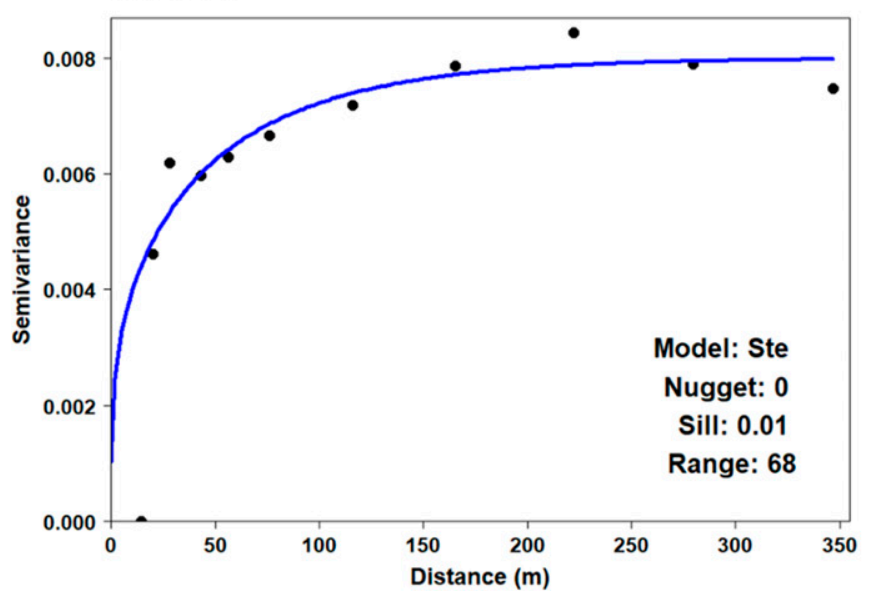

defined by the grid size, and they are as follows: (i) Bin001, 173; (ii) Bin025, 1,493; (iii) Bin026, 317; (iv) Bin054, 76; (v) Bin068, 22; and (vi) Bon064, 151. The densities of cysts per kilogram of soil per foci were (i) Bin001, $3.17 \pm 0.56$; (ii) Bin025, $36.07 \pm 2.39$; (iii) Bin026, 13.49 \pm 1.83; (iv) Bin054, $22.38 \pm 7.74$; (v) Bin068, $5.91 \pm$ 3.34 ; and (vi) Bon064, 5.73 \pm 1.77 . The field Bin025 had the highest level of infestation $(P<0.05)$, with the greatest concentration of foci and cysts located on the northern edge followed by a diffuse wave of infestation toward the southeast corner, with some foci

\section{Bin025}

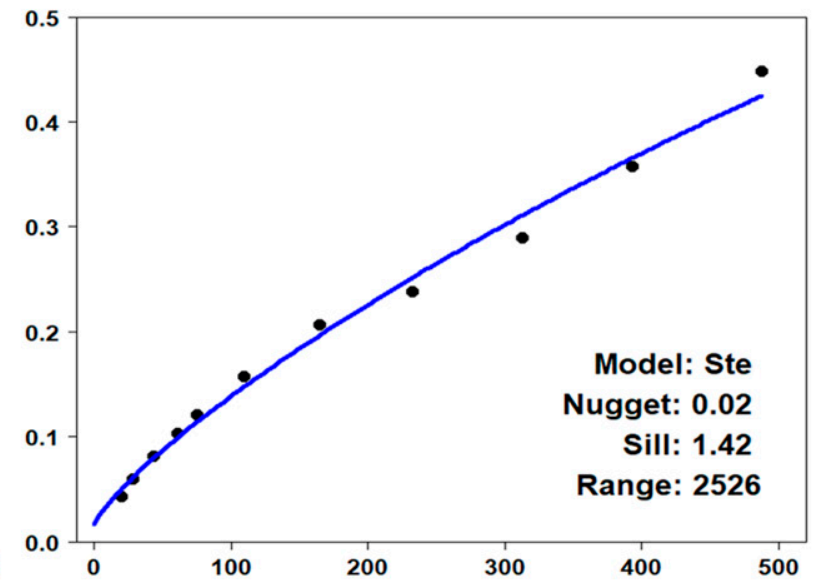

Bin054

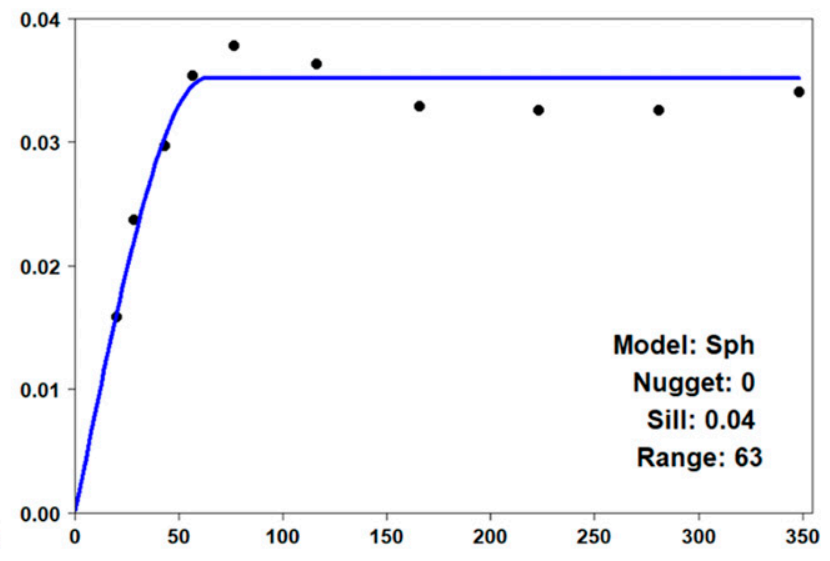

\section{Bon064}

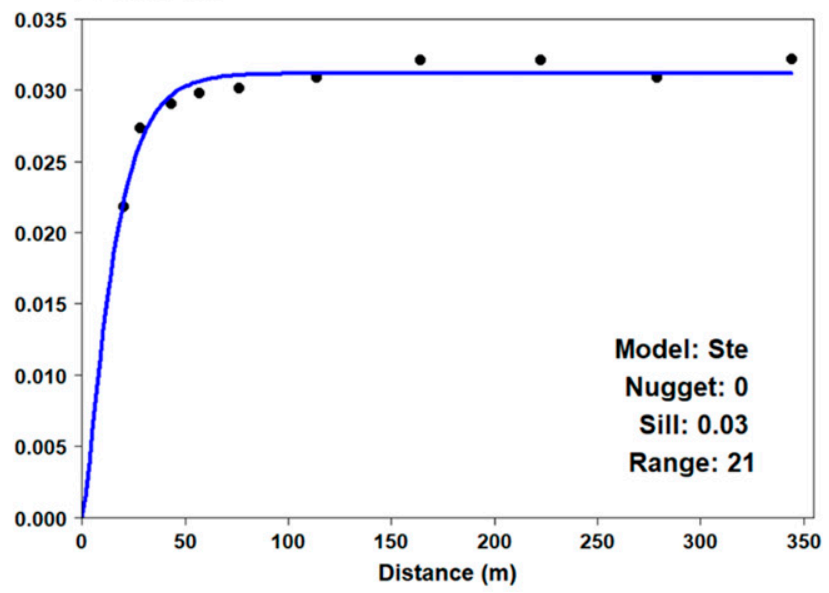

Fig. 3. Experimental variogram and fitted variogram model for fields infested with Globodera pallida. 
advancing toward the center of the field. Similar dispersal patterns were observed for Bin026 and Bin054. We found that the pattern of $G$. pallida spread followed the direction of cultivation and that it was oriented toward the north/south for all fields except for Bon064, which was east/west.

The spatial continuity of cysts for each field using experimental and fitted variogram models was determined. The variograms measured the variability between pairs of cyst data points at various distances and fit a nonlinear model to the coefficients. The results showed the presence of spatial dependence associated with different distance ranges, where the incidence of cysts in the fields correlated with space (Fig. 3). The experimental variograms for all fields were fit using the Ste model (Matern, M. Stein's parameterization) except for Bin054, where a spherical model was used (Fig. 3). The smoothing parameter $\kappa$ values for the model fitting were for (i) Bin001, 0.30; (ii) Bin025 and Bin026, 0.40; (iii) Bin068, 0.20; and (iv) Bon064, 0.80. Bon064 showed the lowest range of spatial continuity because of the increased
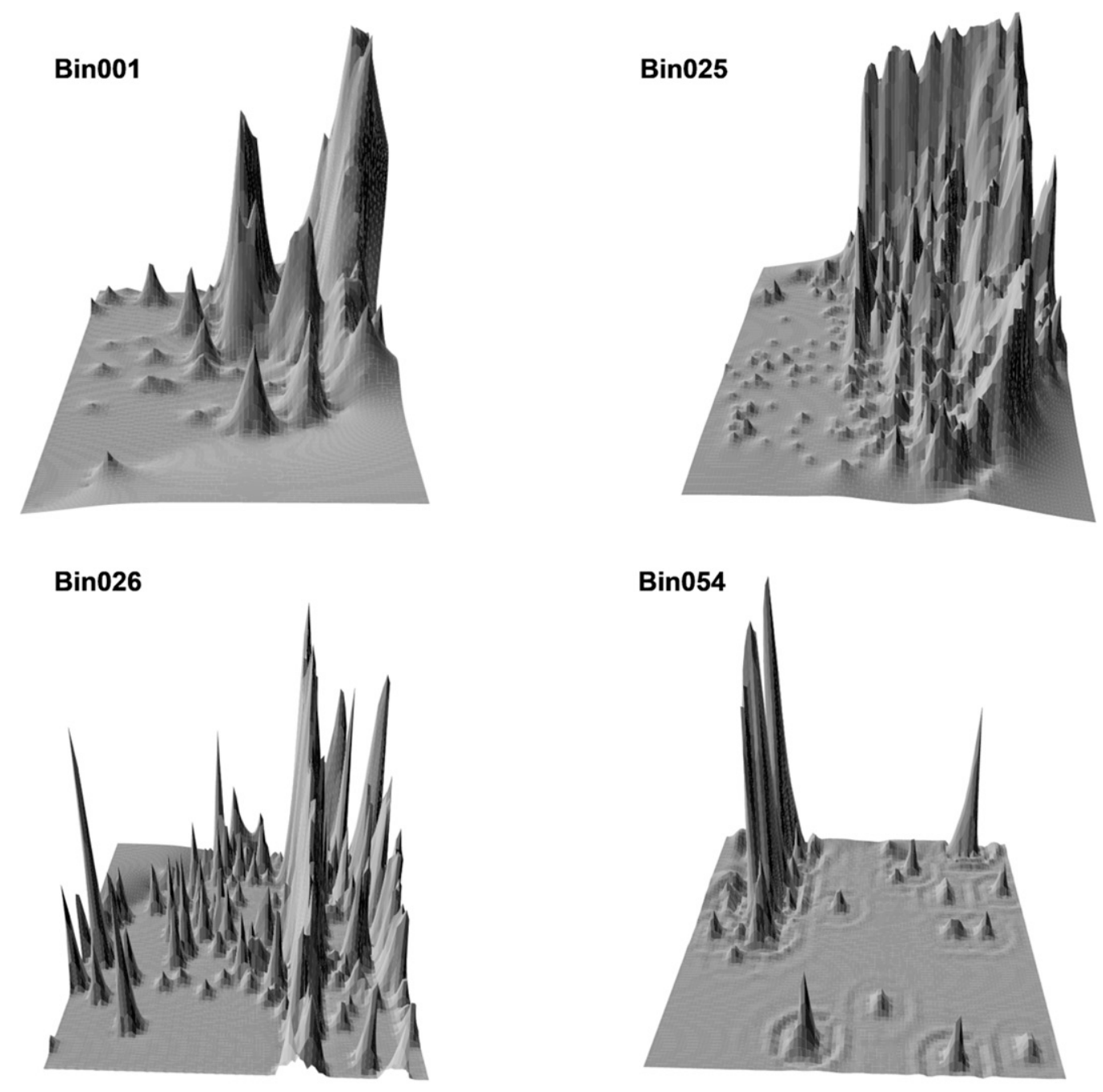

\section{Bin068}
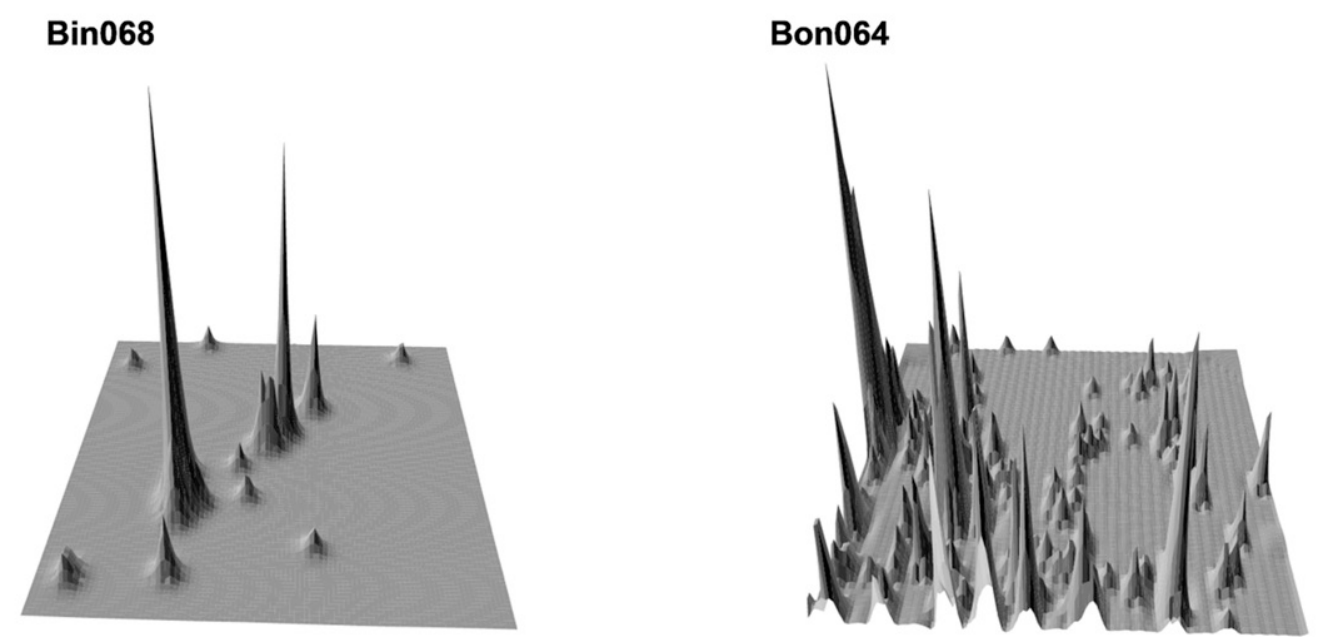

Fig. 4. A three-dimensional spatial kriging simulation of the distribution of Globodera pallida cysts in infested fields. 
level of variabilities in the repartition of cyst densities over the surface area of the field. The field Bin025 illustrated an unbounded variogram (intrinsic process), where autocorrelation increased indefinitely with increasing distances ( $>500 \mathrm{~m}$ of range), mostly because of the vast and continuous extent of the field infestation by the cysts. We investigated the orientation of spatial dependence in each field by using directional variograms, which were computed by using the eight directions north, northeast, east, southeast, south, southwest, west, and northwest. The directional variogram indicated that spatial dependence was the same in all directions for all fields (isotropic process), with the exception of field Bin025, where spatial dependence reached a distance range of $200 \mathrm{~m}$ when oriented toward the southeast and northwest directions of the field (anisotropic process) (Supplementary Fig. S2).

Kriging interpolation methods use both mathematical and statistical tools to predict the incidence of cysts at all locations within the study area, and they also provide prediction errors based

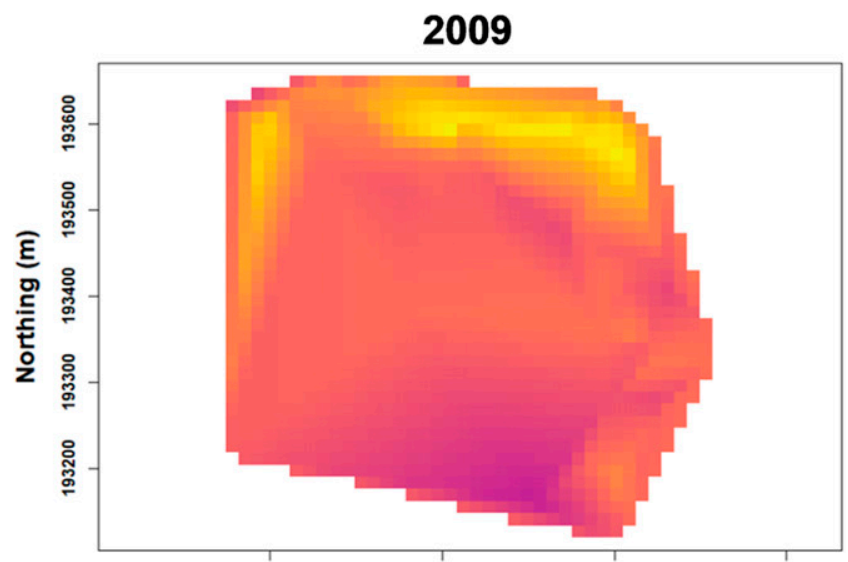

2011

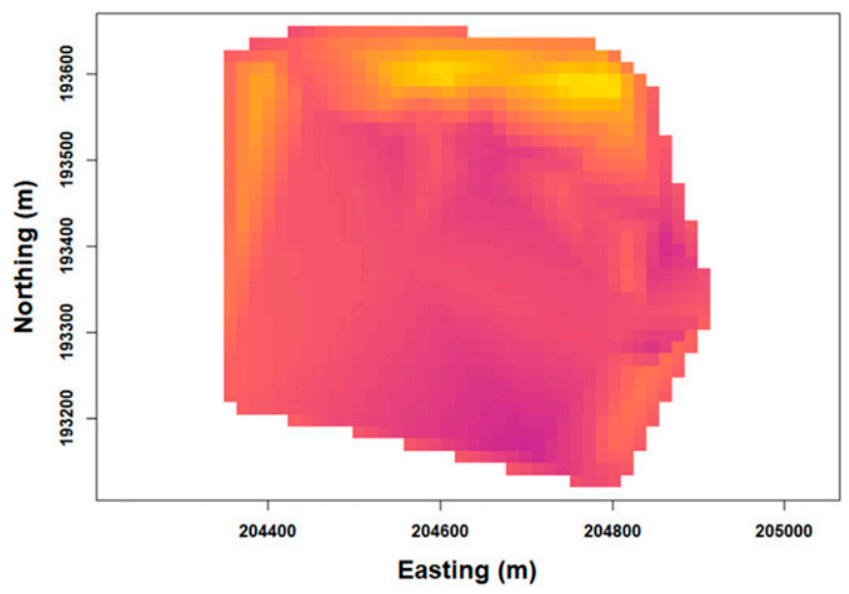

2010
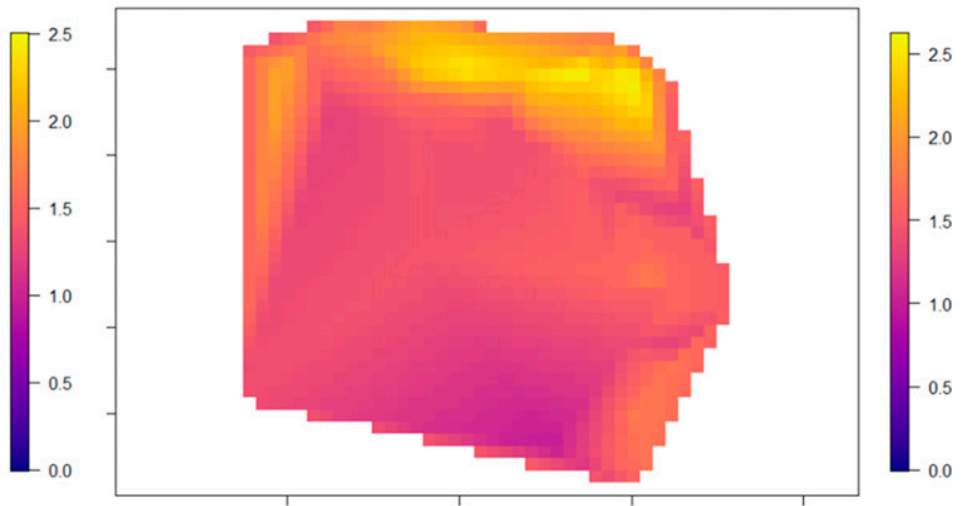

2012

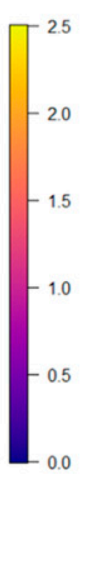

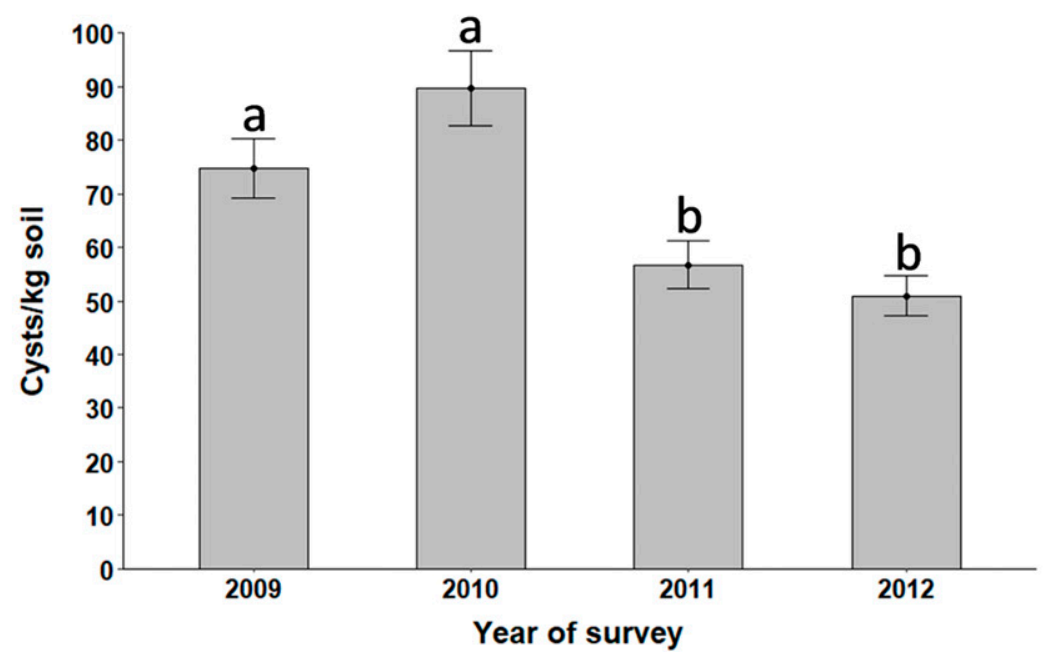

Fig. 5. Spatiotemporal distribution of Globodera pallida cysts in Bin025. The number of cysts is $\log _{10}$ transformed per kilogram of soil in the interpolated maps. The graph below shows the temporal variations in the number of cysts collected in Bin025, and the same letters indicate no significant differences $(P>0.05)$. 
on the spatial autocorrelation among the cyst data points. Ordinary log-normal kriging prediction showed similar cyst distribution patterns in each field compared with the deterministic Akima method, and it was associated with a low level of kriging standard errors (Fig. 4 and Supplementary Figs. S3 and S4). We calculated the index of dispersion to determine whether the distributions of cysts in the fields were clustered or dispersed compared with the randomness associated with a Poisson process, and they were for (i) Bin001, 0.17; (ii) Bin025, 0.08; (iii) Bin026, 0.34; (iv) Bin054, 0.24; (v) Bin068, 0.71; and (vi) Bon064, 0.29. The results showed that the index of dispersion was between $0<D<1$, indicating that the distribution of cysts in the fields was underdispersed or clustered and pointing to a binomial distribution. Bin025 showed the highest degree of nematode clustering (0.08), particularly in the northern part of the field, and Bin068 showed the lowest degree of nematode clustering (0.71).

After the detection of G. pallida, planting potato was prohibited in infested fields. Instead, fields were treated with nematicidal fumigants, and biofumigant cover crops were planted over two seasons. The spatiotemporal analysis of Bin025 was conducted to determine the variations in the number of cysts collected from inception of monitoring to 2018 surveys. No significant increase was found in the number of cysts collected in 2009 and $2010(P>$ $0.05)$ (Fig. 5). However, the density of cysts was significantly less in 2011 and 2012 compared with previous years $(P<0.05)$ (Fig. 5). For Bin026, in the years 2009 to 2012, the variations in number of cysts were significantly less in cysts in 2012 compared with previous years $(23 \%$ less, $P<0.05)$, and egg viability was $0 \%$ by 2012 (Fig. 6).

The force of invasion of G. pallida, which is used to predict the dispersal capabilities of the nematode, was simulated by ISDM for field Bin025. A raster layer was generated in the kriging procedure for the simulation. For the simulation, 30 infestation foci were randomly placed over the field, and ISDM simulated the expansion of the foci using a negative exponential dispersal under nine probability dispersal kernels that reflected the intensity of human activities. As the dispersal kernel increased, the results showed the occurrence of a stratified dispersal mechanism, which consisted of the growth and development of individual nematode foci and the fusion of foci that contributed to the advance of the infestation wave front in the field (Fig. 7).

We estimated the distance separation between the primary nematode inoculum focus in the field and the rest of the infestation foci, and we calculated the percentage of cyst prevalence relative to the primary focus of infestation. We observed a process of nonlinear decline in the prevalence of cysts as the distance separation from the source increased (Fig. 8). The decline in the prevalence of cysts, at a rate between 35 and $48 \%$, presented a very steep gradient near the source and a shallower gradient far from it, which indicated the presence of a traveling wave of infestation. A power law model was fit over the distribution of cyst prevalence to describe the SDD pattern of the nematode in the fields (Fig. 8). The model parameters for the estimates of the power model were significant $(P<0.001)$, and the coefficients of correlation between the observed values and the model prediction values were (i) Bin001, 0.52; (ii) Bin025, 0.44; (iii) Bin026, 0.47; (iv) Bin054, 0.76; (v) Bin068, 0.93; and (vi) Bon064, 0.86. The LDD pattern of G. pallida between the fields was estimated by calculating the distance separation between the most infested field (Bin025) and the rest of the fields. Similar trends in the LDD pattern of the nematode compared with SDD with a fat-tailed distribution were observed as the distance of separation from Bin025 increased

\section{Distribution of cysts}

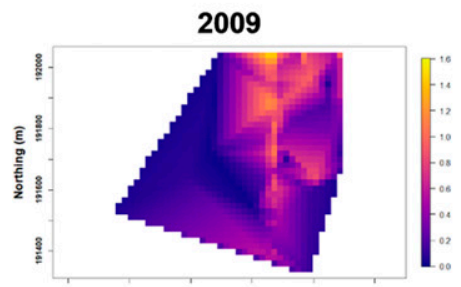

2011
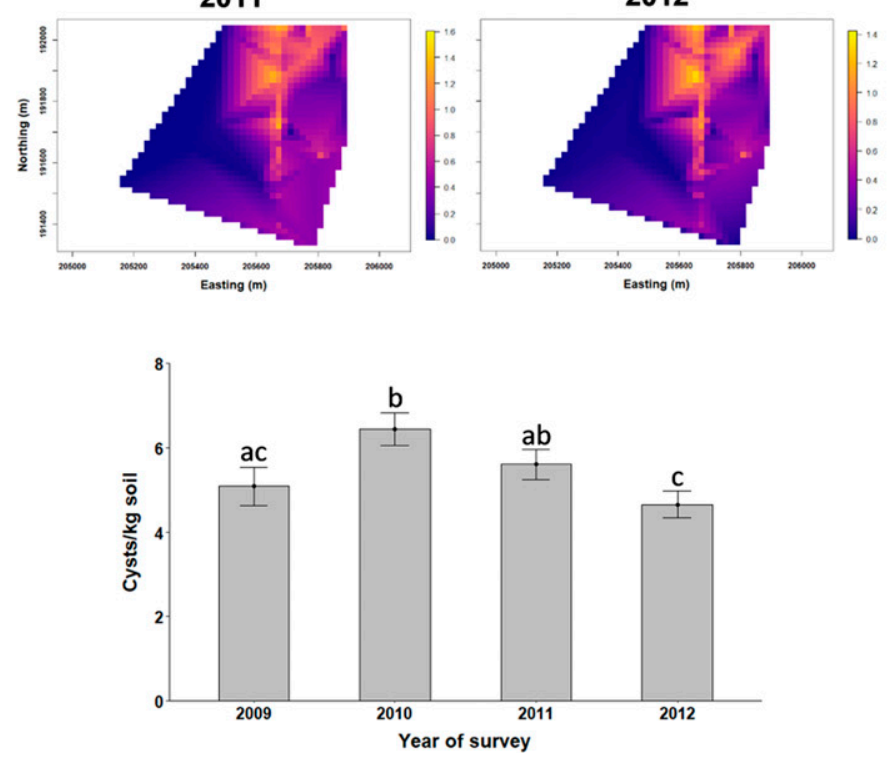

2010

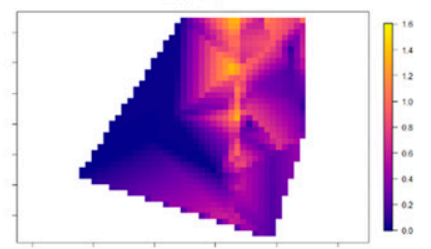

2012
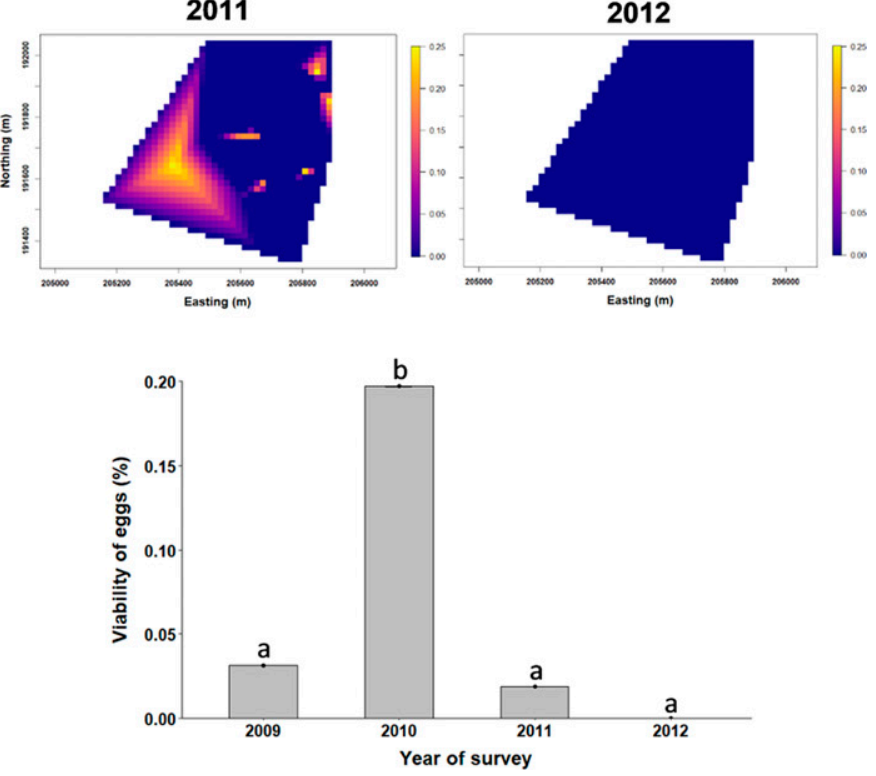

Fig. 6. Spatiotemporal distribution of Globodera pallida cysts and the viability of eggs in Bin026. The number of cysts is $\log _{10}$ transformed per kilogram of soil, and the viability of eggs is expressed as a percentage in the interpolated maps. The graphs below show the temporal variations in the number of cysts and the viability of eggs in Bin026, and the same letters indicate no significant differences $(P>0.05)$. 
(Supplementary Fig. S5). The model parameters for the estimates were significant $(P<0.004)$, and the coefficient of correlation was 0.99 .

\section{DISCUSSION}

Our study provides a comprehensive analysis of the spatiotemporal pattern of G. pallida in Idaho. This study provides the first description of $G$. pallida invasion steps for Idaho using spatial simulations. The spatial patching of plant-parasitic nematodes in the field represents a common attribute of the phylum Nematoda (McSorley 1998). When a susceptible crop is planted on a yearly basis, the nematode population in soil increases, and the patches increment in size; eventually, in time, they will merge. The infestation of $G$. pallida in Idaho started at a few isolated infestation sites. Spatial analysis confirmed that the infestation was highly aggregated. G. pallida spread in Idaho, which started at a couple of isolated infestation patches in Bin068 that would eventually expand to resemble Bin054, and with cultivation, the infestation would be contiguously seeded in the field to resemble Bin026. Finally, after multiple potato plantings, Bin026 would mirror Bin025 with a massive infestation hot spot. We used the ISDM simulation to retrace $G$. pallida invasion steps in a raster-based map, and the model showed similar invasion patterns as described above.

The typical visible symptoms of plant stunting and yellowing caused by this nematode were not observed by Idaho potato growers in the highly infested fields, and if the symptoms were perceived, they could have been wrongly interpreted as nutrient deficiencies or fungal pathogens. The consequences of the detection delay of this nematode contributed to the accumulation of its inoculum, with some potential potato yield reductions in highly infested fields. In a
2019 study, the impact of the G. pallida Idaho population on potato yield was modeled and simulated for Idaho field conditions, and the results showed that, at 80,000 eggs per kilogram of soil or 800 cysts per kilogram of soil, fresh tuber yield loss reached 84 ton/ha in the susceptible cultivar Désirée (Contina et al. 2019). In this study, the highest level of nematode infestations in soil was estimated to 35,660 eggs per kilogram of soil in Bin025, and this corresponded to a fresh tuber yield loss of 42 ton/ha using the simulation described above. The results of this study represent a general basis for promoting further research with spatial simulations of the effect of control measures, such as trap crops, biofumigant extracts, and biocontrol agents, on $G$. pallida distribution and their impact on potato yield (Knudsen et al. 2015).

Ferris et al. (1990) defined two components affecting the spatiotemporal distribution of plant-parasitic nematode populations: (i) the macrodistributional component occurring at the field scale, such as environmental factors defined as soil texture, soil moisture, or drainage pattern and external factors defined as cropping history and differential plant host selection pressure; and (ii) the microdistributional component occurring at a smaller spot scale that is primarily mediated by food resource distribution. Our prediction maps showed several infestation patches distributed across the fields. The macrodistributional component could influence the occurrence of these patches, because the physical characteristics of soil in a given field varied at relatively short distances from one point to another. The rotation system between potato and grain productions used by Idaho potato growers could influence the growth rate of infestation patches in the field, because wheat and barley are nonhosts for the nematode. In the absence of potato, the mortality rate of $G$. pallida and G. rostochiensis was shown to be $69 \%$ in the first year after a potato crop and between 20
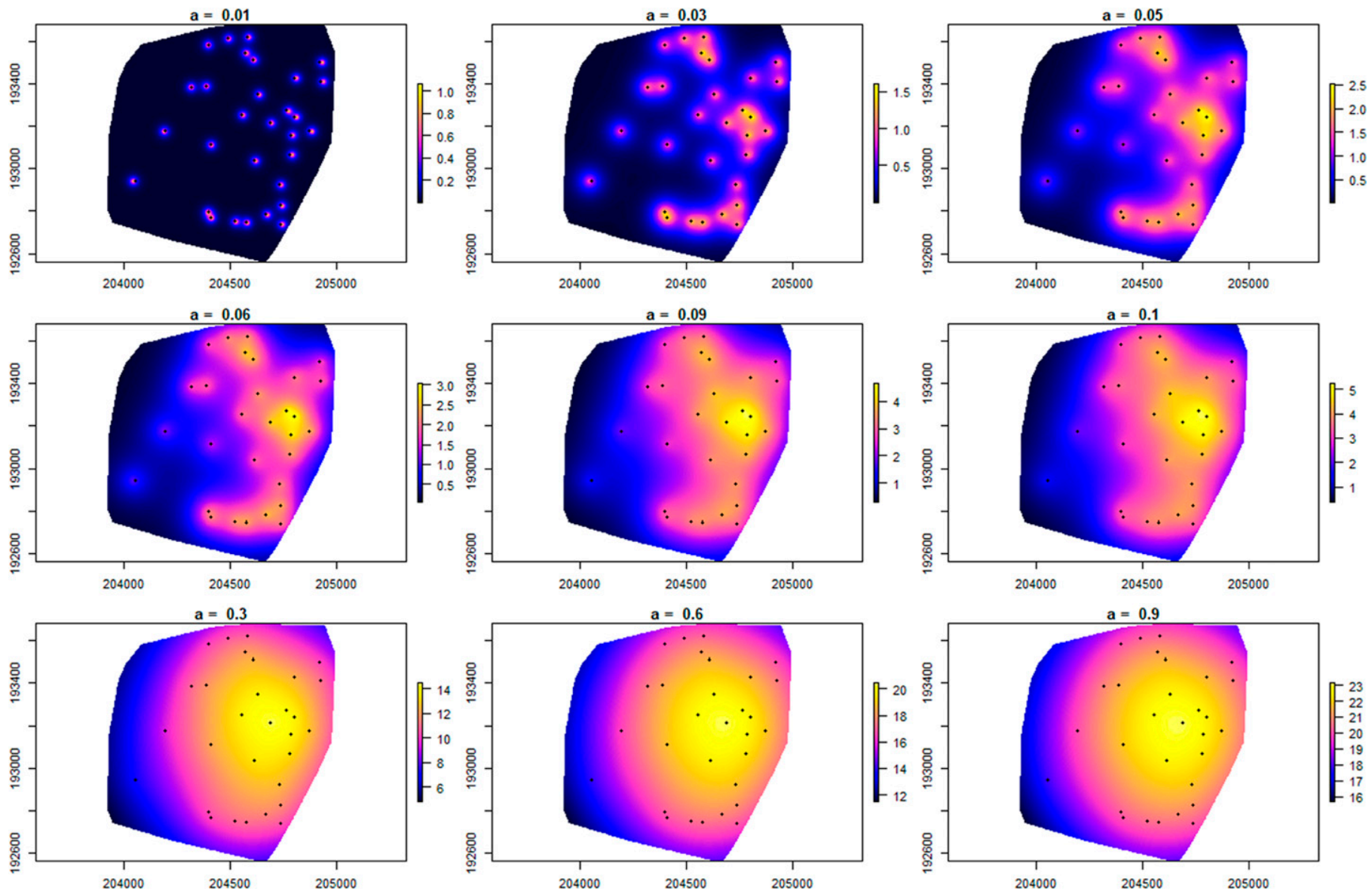

Fig. 7. Simulations of Globodera pallida force of invasion in Bin025 field in the absence of control measures using invasive species distribution modeling to compute negative exponential dispersal patterns with the different probability kernel density function. 
and $30 \%$ in subsequent years; however, nematode populations rebound during the next potato cropping season (Schomaker and Been 2006). Our prediction maps showed the cumulative infestation event and failed to show the cyclical variations during intercropping seasons. Rode (1962) showed that the migration of G. rostochiensis juveniles to the potato roots was greatest in sandy soil, intermediate in loamy soil, and least in clay soil. Tarjan (1971) observed that Radopholus similis migrated better in sandy soil than in heavytextured soil. Holguin et al. (2015) showed that Rotylenchulus reniformis densities in soil peaked when sand content was around $60 \%$ and declined when sand content increased above 60 to $65 \%$. Eberlein et al. (2016) showed that a biotic component could negatively impact nematode reproduction in certain areas of a field, because several cosmopolitan antagonistic microbes are known to reduce and suppress $G$. pallida reproduction rate (Contina et al. 2017; Dandurand and Knudsen 2016; Tobin et al. 2008). The patchy distribution could also be explained by the occurrence of genetic variation in $G$. pallida that could foster the development of metapopulations in different sections across and between fields (Folkertsma et al. 2001; Picard et al. 2004). Although our study was limited on the spatial description of the nematode in fields, the results provided could be used as a basis to formulate other potential research questions on nematode spatial behavior. Future research directions should focus on elucidating the combined influence of biotic and abiotic processes on the occurrence of $G$. pallida infestation patches in fields.

The use of geostatistical tools allows precise mapping and describes the relationship between attribute variables and the spatial configurations. The spatial distribution of nematodes in the field has been described as aggregated, which points to spatial dependence in the sampling data (McSorley 1998; Wallace and Hawkins 1994).
Geostatistics, also known as regionalized variable theory, are better equipped for the analysis of spatially correlated data, because conventional statistics are inadequate to describe data that are spatially correlated (Clark 1979; Cressie 1993; Evans et al. 2003; Wallace and Hawkins 1994). Schomaker and Been (1999) developed a conventional statistical model for describing potato cyst nematode infestation foci based on multiple regression with generalized linear models and classical linear models. However, the authors were unable to account for random spatial variations occurring in the field, because a sample value is expected to be affected by its position and its proximity to neighboring positions.

In our study, we showed that the incidence of $G$. pallida cysts in the field was correlated with space. We found that the spatial dependence was the same in all directions for all fields with a distance range between 21 to $119 \mathrm{~m}$. We also found that it corresponded to an isotropic process except for in Bin025, where spatial dependence reached a distance range of $200 \mathrm{~m}$ when oriented toward the southeast and northwest directions of the field and where it corresponded to an anisotropic process. In our study, short ranges could be defined as the extent level for the presence of spatial autocorrelation for G. pallida when the spatial dependence is associated with isotropic and bounded processes. Shorter ranges for nematode infestations have been previously observed in different landscape systems, including $5 \mathrm{~cm}$ to $50 \mathrm{~m}$ in permanent pasture with Longidorus spp. and Rotylenchus goodeyi (Boag et al. 1998), $70 \mathrm{~m}$ in reed canary grass with Paratylenchus spp. (Wallace and Hawkins 1994), $67 \mathrm{~m}$ in sugarcane crop with nematodes (Criconemella onoensis, Helicotylenchus erythrinae, Hemicriconemoides cocophilus, and Pratylenchus zeae) (Rossi et al. 1996), and 5 to $50 \mathrm{~m}$ in agricultural fields in Scotland with G. rostochiensis and Heterodera avenae (Webster and Boag 1992). Variograms are

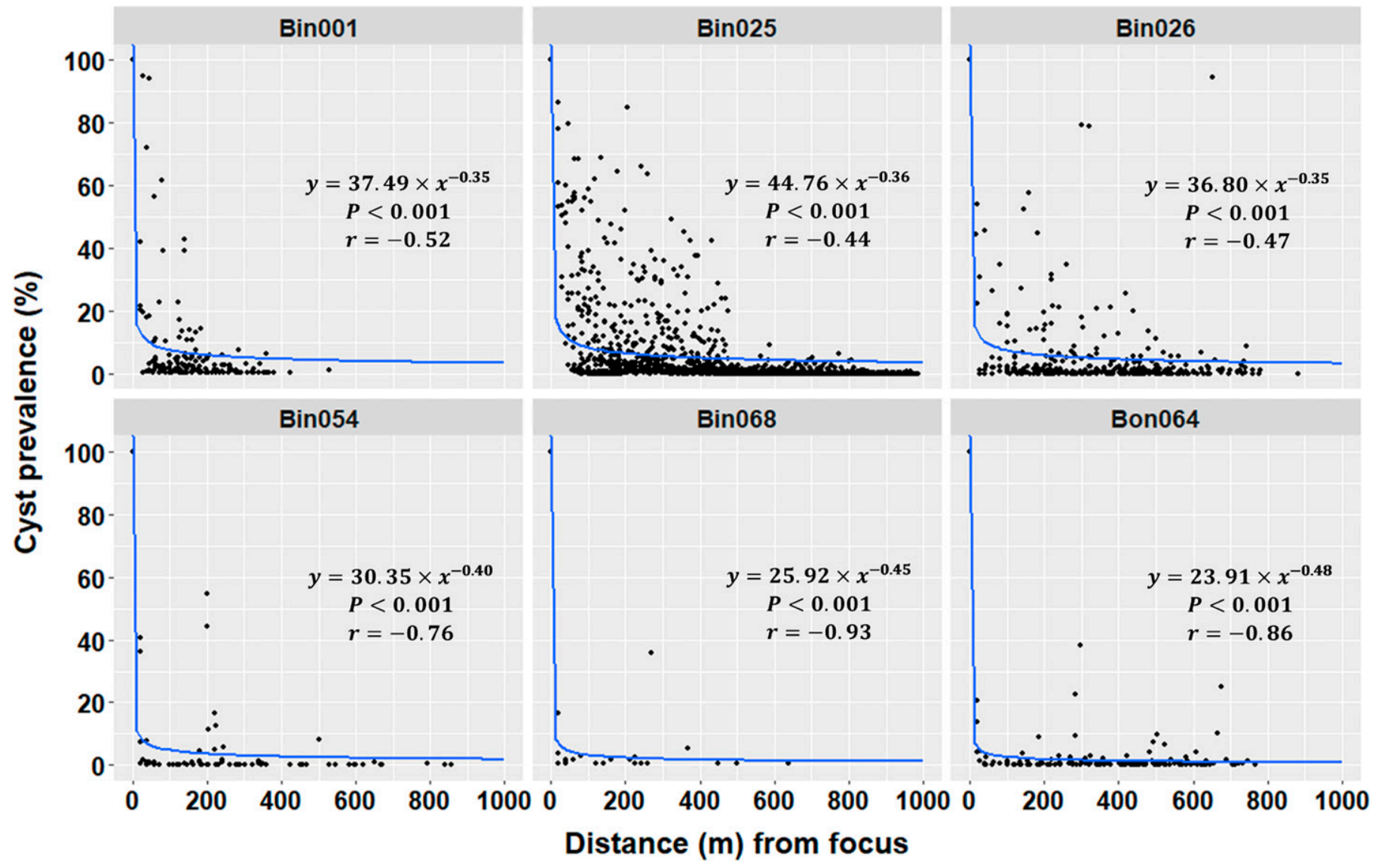

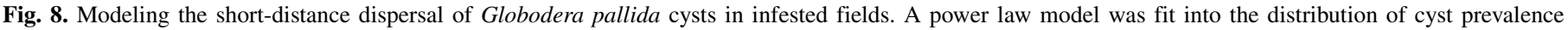
relative to the distance separation from the source of infestation. 
used by kriging stochastic modeling to build a prediction map of the nematode occurrence in a field. Our kriging prediction maps captured the spatial incidence and prevalence of G. pallida as well as the nematode temporal fluctuations in infested fields. The use of geostatistics in plant nematology provides important information on improving nematode sampling efficiency (Dinardo-Miranda and Fracasso 2009; Francl 1986; Wang et al. 2012), determining the ecological patterns of the nematode distribution (Holguin et al. 2015; Porazinska et al. 2012; Rossi et al. 1996), and supporting the use of site-specific management in nematode-infested fields (Avendaño et al. 2003). Evans et al. (2003) used geostatistical techniques to build kriging prediction maps to localize potato cyst nematodes infestation hot spots to generate information on the effects of nematicide applications on the management of nematode populations in the field.

G. pallida produces only one infection cycle per crop cycle and causes the development of a monocyclic epidemic. The epidemic is characterized by a linear production of cysts in soil and a passive dispersal of inoculum in and across fields. The initial nematode density in soil represents a fundamental component for disease prevalence in cumulative period. Modeling the dispersal capabilities of exotic pathogens can provide critical information to phytosanitary agencies for the establishment of a containment perimeter. We found that the dispersal of G. pallida cysts followed a power law distribution, where the prevalence of cysts was sharply reduced as the distance separation from the source of infestation increased. The power law model illustrates a fat-tailed distribution typical for LDD of plant pathogens that will contribute to the progression of the infestation fronts to noninfested areas (Gregory 1968; Madden et al. 2007). The invasion of plant pathogens highlights a traveling wave of conquest, which is amplified by the species reproductive capacity, generation time, and dispersal ability (Mundt et al. 2009). The dispersal of potato cyst nematodes using historical data from Europe has shown that potato cyst nematodes can spread an average distance of $5.3 \mathrm{~km} /$ year from the site of first detection and disperse $212 \mathrm{~km}$ over a span of 40 years before it is detected (Banks et al. 2012). Rising soil temperature owing to climate change could increase potato cyst nematodes survival rates (Skelsey et al. 2018), and it could cause the development of multiple generations of nematodes within one growing season (Kaczmarek et al. 2019), which would increase the number of nematodes in soil and exacerbate the disease epidemic.

The spatiotemporal analyses of G. pallida cysts and the viability of eggs during the years of control and eradication with agrochemical fumigants and biofumigant cover crops indicated that the level of cysts in the field significantly decreased in the absence of potato crop. The phytosanitary measures undertaken by USDA-APHIS and ISDA contributed to a reduction encysted egg viability. The enforcement of quarantine regulation in Idaho has contributed in minimizing the risk of G. pallida spread to noninfested areas and enabled coordination efforts between phytosanitary agencies, stakeholders, and growers to eradicate the initial outbreak. The benefits of excluding nonnative nematodes from potato-growing areas in the United States are estimated to be \$300 million annually (Dwinell and Lehman 2004; Hockland et al. 2006). Hodda and Cook (2009) estimated that the spread of potato cyst nematodes could cause Australian dollar $>\$ 370$ million in economic losses for the Australian agricultural sector if no reactive regulations were enacted. Phytosanitary interventions were critical in stopping the invasion of potato cyst nematodes and eradicating the nematodes before establishment in Israel (EPPO 1987), Australia (EPPO 2010), and Finland (EPPO 2012).

To our knowledge, this study represents the first detailed geospatial analysis of a Globodera species in the United States. The use of both deterministic and stochastic spatial modeling approaches provided consistent results and reinforced the study conclusions. Our study contributed critical information on the invasion process of $G$. pallida as well as the nematode spatial configuration in the Idaho potato cropping system. Furthermore, this study showed the current impact of phytosanitary interventions in containing and eradicating this nematode. Finally, this study highlighted the importance of collaboration between academia, state, and federal phytosanitary agencies in the sharing, analysis, and publication of processed data to inform potato growers, stakeholders, and the public in general on current understandings of this epidemic.

\section{ACKNOWLEDGMENTS}

This project is part of the Ph.D. dissertation of J. B. Contina. We thank T. Gresham of the U.S. Department of Agriculture-Animal and Plant Health Inspection Service for providing the field data for analysis and the senior editor along with the anonymous reviewers for their constructive comments on the manuscript.

\section{LITERATURE CITED}

Akima, H. 1970. A new method of interpolation and smooth curve fitting based on local procedure. J. ACM 17:589-602.

Akima, H. 1991. A method of univariate interpolation that has the accuracy of a third-degree polynomial. J. ACM Trans. Math. Softw. 17:341-366.

Avendaño, F., Schabenberger, O., Pierce, F. J., and Melakeberhan, H. 2003. Geostatistical analysis of field spatial distribution patterns of soybean cyst nematode. Agron. J. 95:936-948.

Banks, N. C., Hodda, M., Singh, S. K., and Matveeva, E. M. 2012. Dispersal of potato cyst nematodes measured using historical and spatial statistical analyses. Phytopathology 102:620-626.

Behrens, E. 1975. Pages 12-26 in: Globodera Skarbilovic, 1959, eine selbstaendige Gattung in der Unterfamilie Heteroderinae Skarbilovic, 1947 (Nematoda: Heteroderidae). Vortragstagung zu aktuellen Problemen der Phytonematologie am 29/5/1975 in Rostock. Manuskriptdruck der Vortraege. Rostock.

Blok, V. C., and Phillips, M. S. 2012. Biological characterization of Globodera pallida from Idaho. Nematology 14:817-826.

Boag, B., Mcnicol, J. W., Marshall, B., and Neilson, R. 1998. A comparison of the spatial distributions of three plant-parasitic nematode species at three different scales. Nematologica 44:303-320.

Boag, B., and Topham, P. B. 1984. Aggregation of plant-parasitic nematodes and Taylor's Power Law. Nematologica 30:348-357.

Bowler, D. E., and Benton, T. G. 2005. Causes and consequences of animal dispersal strategies: Relating individual behavior to spatial dynamics. Biol. Rev. 80:205-225.

CABI. 2018. Globodera pallida (White Potato Cyst Nematode). Centre for Agriculture and Biosciences International. https://www.cabi.org/ISC/datasheet $/ 27033$

Choi, W. I., Jung, H. J., Kim, D. S., Lee, D. S., Lee, C. Y., Nam, Y., Ki, J. B., and Park, Y. S. 2017. Dispersal patterns of Pine wilt disease in the early stage of its invasion in South Korea. Forests 8:411-421.

Clark, I. 1979. Practical Geostatistics. Applied Science Publishers, London, United Kingdom.

Contina, J. B., Dandurand, L. M., and Knudsen, G. R. 2017. Use of GFPtagged Trichoderma harzianum as a tool to study the biological control of the potato cyst nematode Globodera pallida. Appl. Soil Ecol. 115:31-37.

Contina, J. B., Dandurand, L. M., and Knudsen, G. R. 2018. A spatial analysis of the potato cyst nematode Globodera pallida in Idaho. Phytopathology 108:988-1001.

Contina, J. B., Dandurand, L. M., and Knudsen, G. R. 2019. A predictive risk model analysis of the potato cyst nematode Globodera pallida in Idaho. Plant Dis.

Cressie, N. A. C. 1993. Statistics for Spatial Data. Wiley, New York.

Dandurand, L. M., and Knudsen, G. R. 2016. Effect of the trap crop Solanum sisymbriifolium and two biocontrol fungi on reproduction of the potato cyst nematode Globodera pallida. Ann. Appl. Biol. 169:180-189.

Dias, M. C., Conceição, L., Abrantes, I., and Cunha, M. J. 2012. Solanum sisymbriifolium - a new approach for the management of plant-parasitic nematodes. Eur. J. Plant Pathol. 133:171-179.

Dinardo-Miranda, L. L., and Fracasso, J. V. 2009. Spatial distribution of plantparasitic nematodes in sugarcane fields. Sci. Agric. 66:188-194.

Duncan, L. W., Ferguson, J. J., Dunn, R. A., and Noling, J. W. 1989. Application of Taylor's power law to sample statistics of Tylenchulus semipenetrans in Florida citrus. J. Nematol. 21:707-711.

Dwinell, L. D., and Lehman, P. S. 2004. Plant-parasitic nematodes which are exotic pests in agriculture and forestry. Pages 51-70 in: Biological Pollution: An Emerging Global Menace. K. O. Briton, ed. American Phytopathological Society, St. Paul, MN. 
Eberlein, C., Heuer, H., Vidal, S., and Westphal, A. 2016. Microbial communities in Globodera pallida females raised in potato monoculture soil. Phytopathology 106:581-590.

EPPO. 1987. Non-Occurrence of Globodera rostochiensis in Israel. European and Mediterranean Plant Protection Organization (EPPO) Reporting Service No. 18. https://gd.eppo.int/reporting/article-5754

EPPO. 2010. Eradication of Potato Cyst Nematode (PCN) from Western Australia. International Plant Protection Convention (IPPC). https:// www.ippc.int/en/countries/australia/pestreports/2010/09/eradication-ofpotato-cyst-nematode-pcn-from-western-australia/

EPPO. 2012. Situation of Globodera pallida in Finland in 2011. European and Mediterranean Plant Protection Organization (EPPO) Reporting Service No. 04. https://gd.eppo.int/reporting/article-1900

Evans, K., Webster, R., Barker, A., Halford, P., and Russel, M. 2003. Mapping infestations of potato cyst nematodes and the potential for spatially varying application of nematicides. Precis. Agric. 4:149-162.

FAO-IPPC. 2017. Pest Risk Analysis for Quarantine Pests. Food and Agriculture Organization of the United Nations-International Plant Protection Convention. http://www.fao.org/3/a-j1302e.pdf

Ferris, H., Jetter, K. M., Zasada, I., Chitambar, J. J., Venette, R. C., Klonsky, K. M., and Becker, J. O. 2003. Risk assessment of plant-parasitic nematodes. Pages 99-119 in: Exotic ePsts and Diseases: Biology and Economics for Biosecurity. D. A. Summer, ed. Iowa State University Press, Ames, IA.

Ferris, H., Mullens, T. A., and Foord, K. E. 1990. Stability and characteristics of spatial description parameters for nematode populations. J. Nematol. 22: 427-439.

Folkertsma, R. T., van Koert, P., Rouppe van der Voort, J. N. A. M., de Groot, K. E., Kammenga, J. E., Helder, J., and Bakker, J. 2001. The effects of founding events and agricultural practices on the genetic structure of three metapopulations of Globodera pallida. Phytopathology 91:753-758.

Francl, L. J. 1986. Spatial analysis of Heterodera glycines populations in field plots. J. Nematol. 18:183-189.

Gregory, P. H. 1968. Interpreting plant disease dispersal gradients. Annu. Rev. Phytopathol. 6:189-212

Hafez, S. L., Sundararaj, P., Handoo, Z. A., Skantar, M., Carta, L. K., and Chitwood, D. J. 2007. First report of the pale cyst nematode, Globodera pallida, in the United States. Plant Dis. 91:325.

Haining, R. P. 2003. Spatial Data Analysis: Theory and Practice. Cambridge University Press, Cambridge, United Kingdom.

Hattab, T., Garzón-López, C. X., Ewald, M., Skowronek, S., Aerts, R., Horen, H., Brasseur, B., Gallet-Moron, E., Spicher, F., Decocq, G., Feilhauer, H., Honnay, O., Kempeneers, P., Schmidtlein, S., Somers, B., Van De Kerchove, R., Rocchini, D., and Lenoir, J. 2017. A unified framework to model the potential and realized distributions of invasive species within the invaded range. Divers. Distrib. 23:806-819.

Hengeveld, R. 1989. Dynamics of Biological Invasions. Chapman and Hall Ltd., New York.

Hockland, S., Inserra, R. N., Millar, L., and Lehman, P. S. 2006. International plant health: Putting legislation into practice. Pages 327-343 in: Plant Nematology. R. N. Perry and M. Moens, eds. CAB International, Oxfordshire, United Kingdom.

Hodda, M., and Cook, D. C. 2009. Economic impact from unrestricted spread of potato cyst nematodes in Australia. Phytopathology 99:1387-1393.

Holguin, C. M., Gerard, P., Mueller, J. D., Khalilian, A., and Agudelo, P. 2015. Spatial distribution of reniform nematode in cotton as influenced by soil texture and crop rotations. Phytopathology 105:674-683.

Kaczmarek, A. M., Back, M., and Blok, V. C. 2019. Population dynamics of the potato cyst nematode, Globodera pallida, in relation to temperature, potato cultivar and nematicide application. Plant Pathol. 68:962-976.

Knudsen, G. R., Dandurand, L. M., and Contina, J. B. 2015. Modeling trap crop and biocontrol agent effectiveness in management strategies for Globodera pallida. Asp. Appl. Biol. 130:65-74.

Koenning, S. R., Overstreet, C., Noling, J. W., Donald, P. A., Becker, J. O., and Fortnum, B. A. 1999. Survey of crop losses in response to phytoparasitic nematodes in the United States for 1994. J. Nematol. 31: 587-618.

Madden, L. V., Hughes, G., and van den Bosch, F. 2007. The Study of Plant Disease Epidemics. American Phytopathological Society, St. Paul, MN.

Matheron, G. 1963. Principles of geostatistics. Econ. Geol. 58:1246-1266.

McSorley, R. 1998. Population dynamics. Pages 109-133 in: Plant and Nematode Interactions. K. R. Barker, G. A. Perderson, and G. L. Windham, eds. Madison Publishers, Madison, WI.

McSorley, R., Dankers, W. H., Parrado, J. L., and Reynolds, J. S. 1985. Spatial distribution of the nematode community on Perrine marl soils. Nematropica 15:77-92.

Meentemeyer, R. K., Anacker, B. L., Mark, W., and Rizzo, D. M. 2008. Early detection of emerging forest disease using dispersal estimation and ecological niche modeling. Ecol. Appl. 18:377-390.
Mundt, C. C. 1989. Use of the modified Gregory model to describe primary disease gradients of wheat leaf rust produced from area sources of inoculum. Phytopathology 79:241-246.

Mundt, C. C., Sackett, K. E., Wallace, L. D., Cowger, C., and Dudley, J. P. 2009. Long-distance dispersal and accelerating waves of disease: Empirical relationships. Am. Nat. 173:456-466.

Nathan, R. 2001. The challenges of studying dispersal. Trends Ecol. Evol. 16: 481-483.

NCSS. 2002. Bannock Series. National Cooperative Soil Survey. https:// soilseries.sc.egov.usda.gov/OSD_Docs/B/BANNOCK.html

Ogiga, I. R., and Estey, R. H. 1974. The use of Meldola Blue and Nile Blue A for distinguishing dead from living nematodes. Nematologica 20:271-276.

Park, S. J., Taylor, R. A. J., and Grewal, P. S. 2013. Spatial organization of soil nematode communities in urban landscapes: Taylor's Power Law reveals life strategy characteristics. Appl. Soil Ecol. 64:214-222.

Picard, D., Plantard, O., Scurrah, M., and Mugniéry, D. 2004. Inbreeding and population structure of the potato cyst nematode (Globodera pallida) in its native area (Peru). Mol. Ecol. 13:2899-2908.

Porazinska, D. L., Giblin-Davis, R. M., Powers, T. O., and Thomas, W. K. 2012. Nematode spatial and ecological patterns from tropical and temperate rainforests. PLoS One 7:e44641.

R Core Team. 2018. R: A Language and Environment for Statistical Computing. R Foundation for Statistical Computing, Vienna, Austria. http:// www.R-project.org/

Rode, H. 1962. Untersuchungen uber das wandervermogen von Larven des Kartoffelnematoden (Heterodera rostochiensis Woll.) in Modellversuchen mit verschiedenen Bodenarten. Nematologica 7:74-82.

Rossi, J. P., Delaville, L., and Quénéhervé, P. 1996. Microspatial structure of a plant-parasitic nematode community in a sugarcane field in Martinique. Appl. Soil Ecol. 3:17-26.

Sasser, J. N., and Freckman, D. W. 1987. A world perspective on nematology: The role of the society. Pages 7-14 in: Vistas on Nematology. J. A. Veech and D. W. Dickson, eds. Society of Nematologists, Hyattsville, MD.

Schomaker, C. H., and Been, T. H. 1999. A model for infestation foci of potato cyst nematodes, Globodera rostochiensis and G. pallida. Phytopathology 89:583-590

Schomaker, C. H., and Been, T. H. 2006. Plant growth and population dynamics. Pages 275-301 in: Plant Nematology. R. N. Perry and M. Moens, eds. CAB International, Oxfordshire, United Kingdom.

Severns, P. M., Sackett, K. E., Farber, D. H., and Mundt, C. C. 2019. Consequences of long-distance dispersal for epidemic spread: Patterns, scaling, and mitigation. Plant Dis. 103:177-191.

Skantar, A. M., Handoo, Z. A., Carta, L. K., and Chitwood, D. J. 2007. Morphological and molecular identification of Globodera pallida associated with potato in Idaho. J. Nematol. 39:133-144.

Skarbilovich, T. S. 1959. On the structure of the nematodes of the order Tylenchida Thorne, 1949. Acta Parasitol. Pol. 15:117-132.

Skelsey, P., Kettle, H., MacKenzie, K., and Blok, V. 2018. Potential impacts of climate change on the threat of potato cyst nematode species in Great Britain. Plant Pathol. 67:909-919.

Stein, M. L. 1999. Interpolation of Spatial Data: Some Theory for Kriging. Springer Verlag, New York.

Stone, A. R. 1972. The round cyst species of Heterodera as a group. Ann. Appl. Biol. 71:280-283.

Talavera, M., Andreu, M., Valor, H., and Tobar, A. 1998. Nematodos fitoparásitos en áreas productoras de patata de Motril y Salobreña. Invest Agric. Prod. Prot. Veg. 13:87-95.

Tarjan, A. C. 1971. Migration of three pathogenic citrus nematodes through two Florida citrus soils. Soil Crop Sci. Soc. Fla. Proc. 31:253-255.

Timmermans, B. G. H., Vos, J., Stomph, T. J., Van Nieuwburg, J., and Van Der Putten, P. E. L. 2006. Growth duration and root length density of Solanum sisymbriifolium (Lam.) as determinants of hatching of Globodera pallida (Stone). Ann. Appl. Biol. 148:213-222.

Tobin, J. D., Haydock, P. P. J., Hare, M. C., Woods, S. R., and Crump, D. H. 2008. Effect of the fungus Pochonia chlamydosporia and fosthiazate on the multiplication rate of potato cyst nematodes (Globodera pallida and G. rostochiensis) in potato crops grown under UK field conditions. Biol. Control 46:194-201.

Tobler, W. R. 1970. A computer movie simulating urban growth in the Detroit region. Econ. Geogr. 46:234-240.

Turner, S. J. 1996. Population decline of potato cyst nematodes (Globodera rostochiensis and G. pallida) in field soils in Northern Ireland. Ann. Appl. Biol. 129:315-322.

USDA-APHIS. 2009. Pale Potato Cyst Nematode National Survey and Diagnostic Cyst Sample Forwarding Protocols. United States Department of Agriculture's Animal and Plant Health Inspection Service. https:// www.aphis.usda.gov/plant_health/plant_pest_info/potato/downloads/pcndocs/ PCN_NatlSurvey.pdf 
USDA-APHIS. 2017a. Pale Cyst Nematode (PCN) Program Infested Field Deregulation Protocol. United States Department of Agriculture-Animal and Plant Health Inspection Service. https://www.aphis.usda.gov/plant_health/plant_pest_ info/potato/downloads/pcndocs/pcn-infested-field-deregulation-process.pdf

USDA-APHIS. 2017b. Pale Cyst Nematode (PCN) Program Associated Field Deregulation Protocol. United States Department of Agriculture-Animal and Plant Health Inspection Service. https://www.aphis.usda.gov/plant health/plant_pest_info/potato/downloads/pcndocs/pcn-associated-field-deregulation-process.pdf

USDA-APHIS. 2018. Pale Cyst Nematode (PCN) Program Deregulation Protocol for Agricultural Land No Longer in Host Crop Production. United States Department of Agriculture-Animal and Plant Health Inspection Service. https://www.aphis.usda.gov/plant_health/plant_pest_info/potato/ downloads/pendocs/pen-other-deregulation-flowchart.pdf

USDA-APHIS. 2019. Pale Cyst Nematode Eradication Program, 4th Quarter Report (October 1-December 31). United States Department of Agriculture-Animal and Plant Health Inspection Service. https:// www.aphis.usda.gov/aphis/ourfocus/planthealth/plant-pest-and-diseaseprograms/pests-and-diseases/nematode/pcn/ct_pcn_programupdates

USDA-NASS. 2012. Census of Agriculture: Potatoes Harvested. United States Department of Agriculture's National Agricultural Statistics Service. https://www.nass.usda.gov/Publications/AgCensus/2012/Online_Resources/ Ag_Atlas_Maps/Crops_and_Plants/Field_Crops_Harvested/12-M195RGBDot1-largetext.pdf

Vasyutin, A. S., and Yakovleva, V. A. 1998. Globodera in potatoes in Russia. Kartofel. I Ovoshchi 6:29-32.

Wallace, M. K., and Hawkins, D. M. 1994. Applications of geostatistics in plant nematology. J. Nematol. 26:626-634.

Wang, J. F., Stein, A., Gao, B. B., and Ge, Y. 2012. A review of spatial sampling. Spat. Stat. 2:1-14.

Webster, R., and Boag, B. 1992. Geostatistical analysis of cyst nematodes in soil. J. Soil Sci. 43:583-595.

Wollenweber, H. W. 1923. Krankheiten und BeschSdigungen der Kartoffel. Arb. Forsch. Inst. Kartof. 7:1-56. 